\title{
Study on the relationship between the plasma osmotic pressure and concentrations of some metabolites and rumination appearance in sheep
}

\author{
T Fujihara, K Nakamura, T Ichinohe, T Harumoto \\ Shimane University, Faculty of Agriculture, Matsue-shi, Shimane 690, Japan
}

There are some factors which relate the initiation of rumination after eating, and the presence of receptors (chemo-receptor) on the rumen wall already suggested to receive chemical stimuli for initiating rumination ( Fujihara and Nakao 1990, Jpn J Zootech Sci, $61,757-761)$. There may be expected to be some physiological factors associated with rumination(Grovum and Wever, 1992, J Anim Sci, 70, suppl 1315). In the present study, the plasma osmotic pressure, plasma levels of some metabolites and rumination behaviour were investigated in sheep fed various diets.

Expt I: Three sheep weighing $46.8 \pm 5.7 \mathrm{~kg}$, were used. They were fed on timothy hay at $2.0 \%$ as DM per kg BW per day (control period : $\mathrm{H}$ ) and supplemented with rolled barley at $15 \%$ as DM of timothy hay (treatment period : HC). Fresh water and salt licks containing trace minerals were available at all times. One half of the daily ration was given at 09:00 $\mathrm{h}$ and the other half at 21:00 h. A fiveday sampling period, for measuring the time spent chewing during eating and rumination, was preceded by a 7-day preliminary period. On the 1st, 3rd and 5 th days of sampling period, about $10 \mathrm{ml}$ of jugular blood was collected at $0,1,3,6$ and $12 \mathrm{~h}$ after feeding in both periods of control and treatment for measuring osmotic pressure and concentrations of glucose and total protein in the plasma.
Expt II : Three sheep, weighing $44.7 \pm 6.5 \mathrm{~kg}$, were used. They were fed on corn silage at $2.0 \%$ as DM per $\mathrm{kg} \mathrm{BW}$ per day (CS). Other procedures were the same as described in Expt I.

Daily time spent eating corn silage tended to be longer than that with hay alone and hay plus rolled barley while rumination appearance after eating was remarkably longer with CS than with $\mathrm{H}$ and $\mathrm{HS}$. Daily time spent ruminating was slightly shorter with $\mathrm{CS}$ than with $\mathrm{H}$ and $\mathrm{HC}$, and this may be due to a difference of DM intake. The patterns in time course changes of plasma osmotic pressure after feeding were similar for the 3 diets but plasma osmotic pressure level was slightly higher with $C S$ than with $\mathrm{H}$ and $\mathrm{HC}$. The value of plasma osmotic pressure ranged from 270 to 310 for the 3 diets and plasma osmotic pressure tended to increase at 0 to 3 hours after feeding. Plasma total protein concentration increased at one hour after feeding, but plasma glucose concentration decreased within the same period. These findings suggested that changes of plasma osmotic pressure and concentrations of some metabolites could affect rumination appearance.

Table: Eating and rumination behaviour and plasma osmotic pressure for three sheep given hay alone, hay plus rolled barley and corn silage.

\begin{tabular}{lcccc}
\hline & $\mathrm{H}$ & & $\mathrm{HC}$ & $\mathrm{CS}$ \\
\hline Time spent eating $(\mathrm{min})$ & $144.5 \pm 6.0$ & & $136.1 \pm 9.6$ & $159.3 \pm 7.8$ \\
Rumination appearance $(\mathrm{min})$ & $115.3 \pm 14.4$ & & $107.7 \pm 17.1$ & $187.6 \pm 24.5$ \\
Time spent ruminating $(\mathrm{min})$ & $556.9 \pm 15.6$ & & $486.2 \pm 16.0$ & $419.7 \pm 50.5$ \\
Rumination index ${ }^{1}$ & $54.5 \pm 2.3$ & & $49.7 \pm 4.9$ & $72.8 \pm 5.2$ \\
Plasma osmotic pressure & $287.6 \pm 1.3$ & & $287.5 \pm 1.5$ & $295.3 \pm 1.2$ \\
\hline
\end{tabular}

1 Time spent ruminating $/ 100 \mathrm{~g} \mathrm{DM}$ ingested.

Means of 3 sheep $\pm \mathrm{SE}$ 